\title{
PRODUCTION METHODOLOGY OF IRON BASED AMORPHOUS MATERIALS FOR FURTHER BOOST IN ALLOY PROPERTIES
}

\author{
Bartosz PŁOSZAJ 1,* \\ ${ }^{1}$ Chair of Physics, Faculty of Production Engineering and Materials Technology, Czestochowa \\ University of Technology, 19 Armi Krajowej Str., 42-200 Częstochowa, Poland
}

\begin{abstract}
Efficiency and the protection of natural environment are the main requirements for modern materials. Taking into consideration applications for electronics and electrotechnics bulk metallic glasses even after at least 20 years of research still have possibility of improvement. Production of such materials is difficult, however there is probability to boost properties by heat treatment for fast-cooled iron-based alloys. Changes in amorphous structure have impact on magnetic properties, however resources about them are limited. This article focuses on production methodology of iron based amorphous materials using injection, known method but with slightly changed parameter. By this method based alloy with composition of $\mathrm{Fe}_{60} \mathrm{Co}_{10} \mathrm{Y}_{10} \mathrm{~B}_{20}$ was produced. Alloy analysis via $x$-ray diffraction was conducted as the first step before research on magnetic properties of alloy.
\end{abstract}

Keywords: amorphous materials, bulk metallic glasses, fast-cooled iron-based alloys, injection methods.

\section{Introduction}

For modern materials applicable in electronics and electrotechnics main requirements are not only efficiency but also low negative impact on natural environment [1]. More than 20 years of research still give possibility to improve bulk metallic glasses properties [2]. In case of this studies main object is Fe-based amorphous alloy. Primary motivation for using such alloys in the context of electric power grid was the result of 1973 oil crisis. Seven years later in United States Fe-based amorphous alloys cores inside distribution transformers were realized. In 1988 small additive of $\mathrm{Nb}$ and $\mathrm{Cu}$ to $\mathrm{Fe}-\mathrm{Si}$ - $\mathrm{B}$ amorphous alloys resulted in excellent soft magnetic properties after annealing. Then since 1993 FINEMET and VITROPREM were commercially available. In 2007 nanocrystalline $\mathrm{Fe}-(\mathrm{Si})-\mathrm{Cu}-\mathrm{B}$ alloys without addition of $\mathrm{Nb}$ were produced. 2017 resulted with $\mathrm{Fe}-\mathrm{B}(-\mathrm{Cu})$ soft magnetic alloys with ultra-high heating rate [3]. In $2019 \mathrm{M}$. Nabiałek et al state that characterization of structure in ferromagnetic amorphous alloys is difficult. There is also observation that amount of publication about changes in amorphous structure and their influence of magnetic properties of alloys [4]. Following the history emerge strategy in which fields is possibility to boost properties according to requirements for modern materials. To obtain amorphous properties of alloy such should undergo precisely controlled production steps. Instead of relatively new approach of production by laser powder bed fusion [5] classical method of production by injection was selected. As it is known obtaining amorphous structure of metal based alloys is laborious. Bulk metallic glasses might be manufactured by rapid cooling process, which obstruct long-distance movement of particular atoms. In this material chemical short-range order is visible. A. Inoue highlight importance of three empirical rules in bulk amorphous alloys. Such are: multicomponent systems where is more than three elements, difference in atomic ratio not less than $12 \%$ according to three main constituent elements and negative heats of mixing of 
them [6]. Bulk metallic glasses have unique properties (high thermal stability, physical, mechanical and chemical properties) and proper understanding and improvement of glass forming ability has an important role. This ability might be controlled by minor additions role to formation, crystallization, thermal stability and properties improvement of bulk metallic glasses [7]. B addition till 10\% of alloy volume improve glass forming ability. Addition of this element increase stability of present amorphous phase and resulted in low tendency to glassy structure in Fe-based alloys [8].

This article focuses on production methodology of iron based amorphous materials by injection. By this method Fe-Co-Y-B based alloy was produced according to mentioned rules and taking into consideration objective of work. Alloy analysis via $\mathrm{x}$-ray diffraction was conducted as the first step before research on magnetic properties of alloy.

\section{Production Methodology}

There are two main steps to produce sample with demanded properties. First one is focused on production of a polycrystalline ingot. To produce such ingot arc melting in a protective atmosphere of argon is done. All alloy high purity $(99,99 \%)$ components are weighed. Accuracy is at level of $0.0001 \mathrm{~g}$. All weighted components of alloy were carefully placed in a bay on watercooled cooper plate. A high vacuum inside the working chamber is obtained by vacuum and diffusion pumps. Between each pumping chamber is rinsed with argon. Alternating pumping and rinsing is repeated at least three times. The main aim of this alternating procedure is cleaning of the working chamber. All impurities inside chamber have negative impact on the quality of the produced ingot. There is possibility that inside chamber even after pumping and rinsing procedure still impurities are presented. Hence, to remove all unwanted residuents pure titanium is melted before melting of weighted and carefully placed elements. Ingot is re-melted repeatedly from each side. Please notice that reversal of the ingot is done by the manipulator without opening the working chamber. Reversing and re-melting of the ingot assure good mixing of all alloy elements. Good mixing provide homogeneity of the polycrystalline ingot, which has great impact on the reproducibility during the production of fast-cooled iron-based alloys.

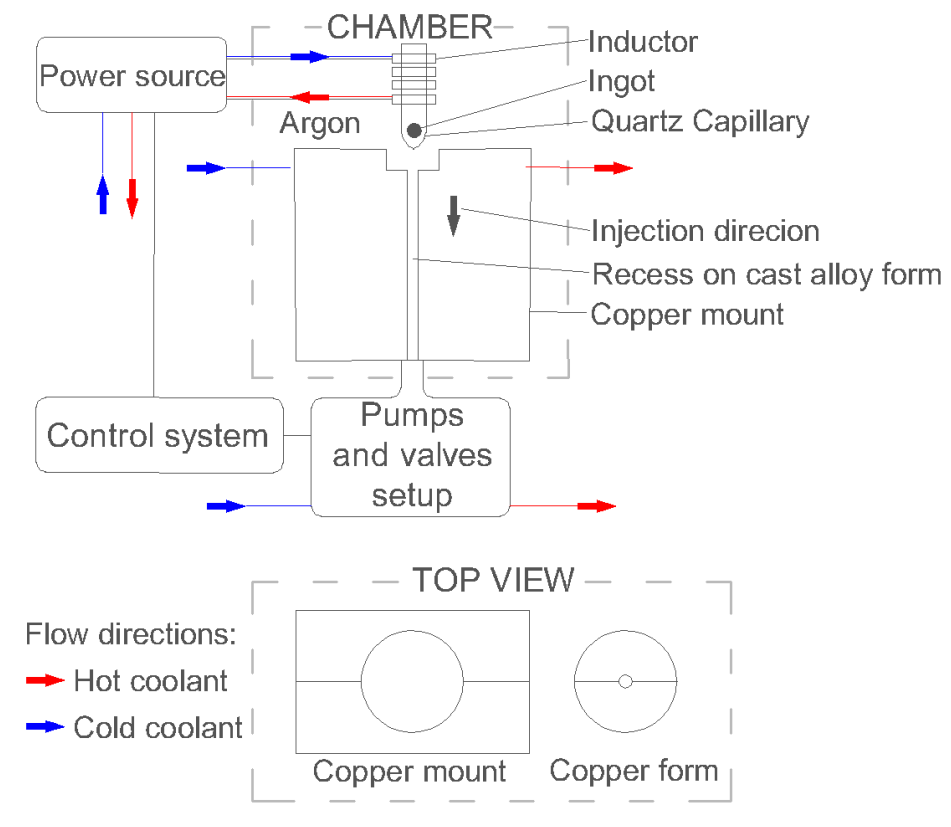

Fig. 1 - scheme of injection casting method for production of amorphous materials 
To produce bulk amorphous alloys second step, have to be done. In our case rapid cooled alloy is made by injection. The one is characterized by a cooling rate between $10^{-1}$ to $10^{3} \mathrm{~K} / \mathrm{s}$. Fig. 1 presents scheme of injection casting method for production of amorphous materials. In this method firstly previously, produced ingot have to be cleaned mechanically and by ultrasonic cleaner. Then ingot is divided to smaller parts to fit size of quartz crucible and is placed as batch inside one. Quartz crucible has a hole roughly about $1 \mathrm{~mm}$ diameter. Inside working chamber crucible is placed in such way, that the batch is between the copper coil. After placing process chamber is pumped by vacuum, diffusion pumps and valves system. Pumping eliminate air or, if present, any unwanted residues. Before sample production under protective atmosphere of argon at least three argon washings between pumping occurred. Eddy currents are used for batch melting. In this case current is exactly 10,9A, instead of usually used 10A in this device. Suitably selected argon pressure is used for pressing liquid melt to the water-cooled copper form. Copper form is presented on fig. 2 . Selected copper form allows to produce $1 \mathrm{~mm}$ diameter rods. Produced rods are carefully removed from the form and then selected to research. Selected samples undergo low energy milling. Such powder is then analysed via x-ray diffractometer.

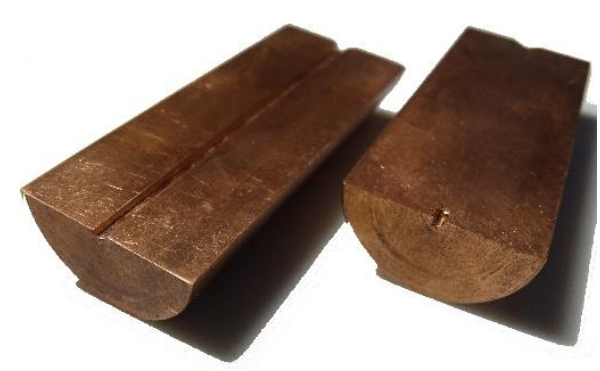

Fig. 2. copper form used to produce rods

\section{Material and Research Methodology}

For purpose of this research following alloy composition $\mathrm{Fe}_{60} \mathrm{Co}_{10} \mathrm{Y}_{10} \mathrm{~B}_{20}$ was selected. Components used for alloy were $99.99 \%$ purity. Proper amount of each were weighted and melted in arc furnace to form 10-gram polycrystalline ingot. By injection selected alloy was placed into a water-cooled copper form to obtain rapid cooled sample. The one was cast in the form of a $1 \mathrm{~mm}$ diameter rods. Mechanical cleaning and ultrasonic cleaning were done for produced sample. Rods were undergone milling process (with low-energy). In fig. 2 obtained samples as ingot and rod are presented.
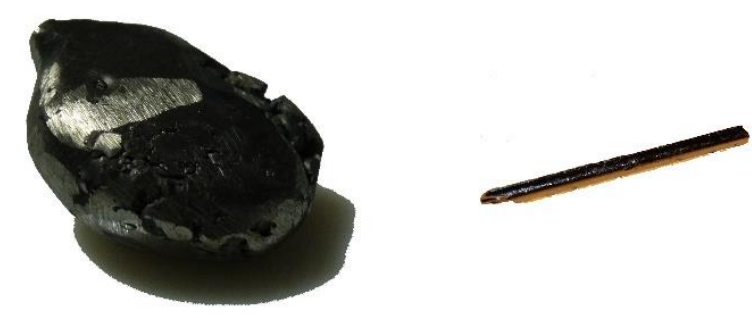

Fig. 3. produced ingot (after mechanical cleaning) and rod 
Powder was examined via x-ray diffractometry to check amorphous properties and potential for further research. Diffractometer is presented in fig. 3.

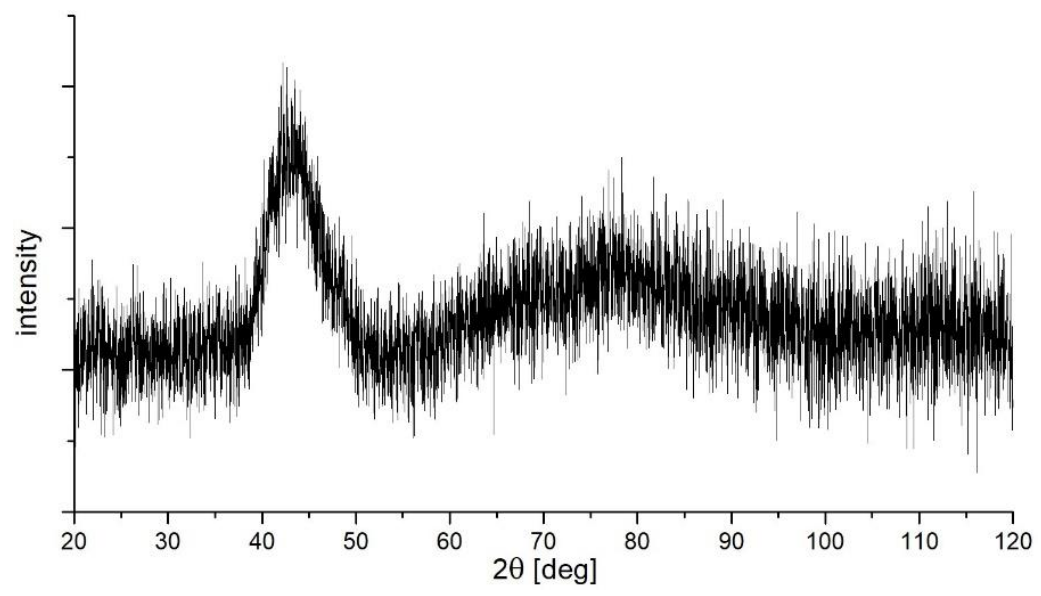

Fig. 4. Diffractometer of the $\mathrm{Fe}_{60} \mathrm{Co}_{10} \mathrm{Y}_{10} \mathrm{~B}_{20}$

The diffraction pattern for this sample is typical as for amorphous alloys. Typical pattern in which there is no long-range atom order occurs for this sample. Maxima is visible about an angle of $2 \Theta 45^{\circ}$. There is no evidence for presence of crystalline phase due to lack of their maxima.

\section{Conclusions}

Analysis via $\mathrm{X}$-ray diffraction was conducted and confirm amorphous structure of produced $\mathrm{Fe}_{60} \mathrm{Co}_{10} \mathrm{Y}_{10} \mathrm{~B}_{20}$ alloy. This alloy, if met demanded approaches such as efficiency and be by the properties environmentally friendly has opportunity to be used in applications for electronics and electrotechnics. For further research is possible to check and boost properties by heat treatment for this alloy. Heat treatment of amorphous structure in this case might have impact on magnetic properties. Hence, it is necessary to conduct magnetic properties test.

\section{References}

[1] P. Vizureanu, M. Nabiałek, A. V. Sandu, B. Jeż, Investigation into the Effect of Thermal Treatment on the Obtaining of Magnetic Phases: $\mathrm{Fe}_{5} \mathrm{Y}, \mathrm{Fe}_{23} \mathrm{~B}_{6}, \mathrm{Y}_{2} \mathrm{Fe}_{14} \mathrm{~B}$ and aFe within the Amorphous Matrix of Rapidly-Quenched $\mathrm{Fe}_{61+x} \mathrm{Co}_{10-x} \mathrm{~W}_{1} \mathrm{Y}_{8} \mathrm{~B}_{20}$ Alloys (where $x=0,1$ or 2), Materials, 13, 835, 2020.

[2] P. Pietrusiewicz, M. Nabiałek, J. Olszewski, S. Lesz, The influence of an isothermal annaling process on the structure and magnetic properties of the bulk amporphous alloy FeCoBYMo, Materiali in Tehnologije/Materials and Technology, 51, 2017, pp. 157-162.

[3] D. Azuma, N. Ito, M. Ohta, Recent progress in Fe-based amorphous and nanocrystalline soft magnetic materials, Journal of Magnetism and Magnetic Materials, 501, 2020.

[4] M. Nabiałek, B. Jeż, K. Błoch, J. Gondro, K. Jeż, A.V. Sandu, P. Pietrusiewicz, Relationship between the shape of $X$-ray diffraction patterns and magnetic properties of bulk amorphous alloys Fe65Nb5Y5+xHf5-xB2O (where: $x=0,1,2,3,4,5)$, Journal of Alloys and Componuds, 820, 2020. 
[5] N. Luo, C. Scheiter, N. Ciftci, F. Galgon, Z. Fu, V. Uhlenwinkel, M. Schmidt, C. Körner, Preparation of $\mathrm{Fe}$-Co-B-Si-Nb bulk metallic glasses by laser powder bed fusion: Microstructure and properties, Materials Characterization, 162, 2020.

[6] A. Inoue, Stabilization of metallic supercooled liquid and bulk amorphous alloys, Acta Materialia, 48, 2000, pp. 279-306.

[7] W. H. Wang, Roles of minor additions in formation and properties of bulk metallic glasses, Progress in Materials Science, 52, 2007, pp. 540-596.

[8] H. R. Lashgari, D. Chu, Shishu Xie, H. Sun, M. Ferry, S. Li, Composition dependence of the microstructure and soft magnetic properties of Fe-based amorphous/nanocrystalline alloys: A review study, Journal of Non-Crystalline Solids, 391, 2014, pp. 61-82.

Received: April 25, 2020

Accepted: May 28, 2020 